\title{
Alternative solutions and new scenarios for translesion DNA synthesis by human PrimPol
}

\author{
María I. Martínez-Jiménez a , Sara García-Gómez ${ }^{\mathrm{a}, 1}$, Katarzyna Bebenek ${ }^{\mathrm{b}}$, \\ Guillermo Sastre-Moreno ${ }^{a}$, Patricia A. Calvo ${ }^{a}$, Alberto Díaz-Talavera ${ }^{a}$, \\ Thomas A. Kunkel ${ }^{\mathrm{b}}$, Luis Blanco ${ }^{\mathrm{a}, *}$ \\ a Centro de Biología Molecular Severo Ochoa (CSIC-UAM), Madrid 28049, Spain \\ b Genome Integrity and Structural Biology Laboratory, National Institutes of Health, Research Triangle Park, NC 27709, United States
}

\section{A R T I C L E I N F O}

\section{Article history:}

Received 10 November 2014

Received in revised form 12 February 2015

Accepted 13 February 2015

Available online 23 February 2015

\section{Keywords:}

PrimPol

DNA primase

DNA polymerase

8oxoG

Lesion bypass

Translesion synthesis

\begin{abstract}
A B S T R A C T
PrimPol is a recently described DNA polymerase that has the virtue of initiating DNA synthesis. In addition of being a sensu stricto DNA primase, PrimPol's polymerase activity has a large capacity to tolerate different kind of lesions. The different strategies used by PrimPol for DNA damage tolerance are based on its capacity to "read" certain lesions, to skip unreadable lesions, and as an ultimate solution, to restart DNA synthesis beyond the lesion thus acting as a TLS primase. This lesion bypass potential, revised in this article, is strengthened by the preferential use of moderate concentrations of manganese ions as the preferred metal activator. We show here that PrimPol is able to extend RNA primers with ribonucleotides, even when bypassing 8 oxoG lesions, suggesting a potential new scenario for PrimPol as a TLS polymerase assisting transcription. We also show that PrimPol displays a high degree of versatility to accept or induce distortions of both primer and template strands, creating alternative alignments based on microhomology that would serve to skip unreadable lesions and to connect separate strands. In good agreement, PrimPol is highly prone to generate indels at short nucleotide repeats. Finally, an evolutionary view of the relationship between translesion synthesis and primase functions is briefly discussed.
\end{abstract}

(c) 2015 Elsevier B.V. All rights reserved.

\section{Introduction}

\subsection{The priming problem and solutions}

It is commonly accepted that DNA polymerases require a primer to initiate DNA synthesis, whereas RNA polymerases do not. Strictly, RNA polymerases do also require a "primer", but that requirement can be fulfilled by a NTP molecule, whose $3^{\prime}-\mathrm{OH}$ acts as the attacking nucleophyle on a second NTP, to form a dinucleotide. Most DNA polymerases cannot do that and requires a pre-existing primer to provide the free hydroxyl group to transfer the next nucleotide [1]. Because of that limitation, a variety of independent solutions have evolved to address the "priming problem". To initiate DNA replication, some DNA polymerases can use special, non-orthodox primers as tRNA (reverse transcriptases)

\footnotetext{
* Corresponding author. Tel.: +34 911964685; fax: +34 911964420.

E-mail address: lblanco@cbm.csic.es (L. Blanco).

1 Present address: DNA Damage Response Laboratory, London Research Institute, Cancer Research UK, Clare Hall, South Mimms EN6 3LD, UK.
}

or terminal proteins (DNA polymerases from ø29-like phages, adenoviruses, and some linear phages), which provide the $3^{\prime}-\mathrm{OH}$; thus, the very same enzyme performs the initiation reaction and the subsequent elongation of the DNA chain [2]. A simpler solution is the use of a "nick" introduced in double-stranded circular DNA (as in parvoviruses, geminiviruses and circoviruses and many phages and plasmids) to obtain the needed "primer" to trigger rolling-circle replication [3]. Another solution is valid for DNA polymerases involved in DNA repair and damage tolerance: different DNA intermediates (i.e. a nick, a gap, or a DSB) provide their 3'-end as a primer [4]. However, in all cellular life forms and many DNA viruses, phages and plasmids, a short piece of RNA is the prevalent primer used for replicative DNA polymerases. Who makes these primers? Exceptionally, those RNA primers can be directly provided by the transcription activity of monomeric RNA polymerases (as in the case of plasmid ColE1 replication or mitochondrial DNA replication), but in most cases they are produced by specialized polymerases named "primases" [5]. Primases can be divided in two evolutionarily unrelated families: DnaG-like primases (bacterial), having a "Toprim" fold, and AEP-like primases (Archaea and Eukaryotes), having a "RRM" fold [6,7]. About 30 
years ago, a specific mitochondrial primase was proposed to exist [8-10], but its identification and functional role in mitochondrial DNA replication has been a matter of debate $[11,12]$. More recent work provided evidence that the mtRNA polymerase is the enzyme acting as a primase, not only to prime leading strand synthesis at OriH, but also to prime the lagging strand at OriL [13].

\subsection{PrimPol, an ancient solution to start DNA synthesis}

A tighter coupling between primase and polymerase function has been described in certain plasmids [14], archea [15] and even bacteria [16], in which a single protein, named PrimPol, performs both RNA polymerase (primer synthesis) and DNA polymerase (DNA synthesis) activities. Amino acid sequence comparisons and 3D-structural analysis [7,16,17] indicated that these bifunctional DNA primase-polymerases (PrimPol) belong to the AEP superfamily, although in these cases, the AEP domain is fused to a helicase domain that can belong to different superfamilies (revised by Ref. [16]). It is worth noting that not all members belonging to the AEP-family function as a primase (or have primase activity). The polymerization domain of Mycobacterium tuberculosis LigD (MtPolDom) is a very interesting example. MtPolDom belongs to the AEP family of primases, but is not able to make a dinucleotide primer, as it cannot bind a ribonucleoside triphosphate at the $5^{\prime}$-side of the reaction (the primer site); conversely, a preexisting primer (the $3^{\prime}$-protruding end of a double-strand break) binds the $5^{\prime}$-site, and it can be extended with a NTP selected by the $3^{\prime}$-protrusion (acting as template) of a second DNA end, allowing its function in bacterial NHEJ $[4,18,19]$. Accordingly, MtPolDom is not fused to a helicase, but to both nuclease and ligase domains.

Based on in silico analysis, a second AEP was predicted to exist in human cells [7]. A detailed biochemical analysis of this putative new enzyme [20] allowed us to demonstrate two specific features: (1) its ability to start DNA chains with deoxynucleotides, unlike regular primases that use exclusively ribonucleotides; (2) its intrinsic DNA polymerase activity (the 17th discovered in human cells), tailored to bypass certain lesions, specially 8-oxoguanine (8oxoG), the most common oxidative lesion in DNA. Based on these features, the HUGO committee of human gene nomenclature accepted our proposal of naming this enzyme PrimPol (PRIMPOL for the gene). Fortunately, other reports describing the identification of the same enzyme used the same nomenclature [21,22].

Subcellular fractionation and immunodetection studies indicated that PrimPol is present in both nuclear and mitochondrial DNA compartments [20]. In these two compartments, the complement of polymerases involved in DNA synthesis significantly differs (see Fig. 1A). In mitochondria, initiation of DNA replication at both OriH and OriL is primed by the mitochondrial RNA polymerase (POLMRT), and these two single primers (one for each strand) are supposed to be processively elongated by Pol $\gamma$, the mitochondrial replicase. Nuclear DNA replication, a much larger task, employs a dedicated two-subunits primase (Pri1 + Pri2) to make RNA primers, that will be "transformed" in DNA primers by their extension with dNTPs by a specific, proofreading-deficient DNA polymerase (Pol $\alpha)$, being further transferred to the distinct replicases Pol $\varepsilon$ and Pol $\delta$, operating either at the leading or the lagging strand, respectively. On top of that, PrimPol offers a third choice for priming (see Fig. 1A), as PrimPol is able to start synthesis with dNTPs, thus producing mostly DNA primers, although it is quite likely that in vivo a purine ribonucleotide occupies the $5^{\prime}$-position of the synthesized primer [20]. Not surprisingly, both primase and polymerase activities of PrimPol share the same catalytic active site (conserved in the AEP family). Fig. 1B shows a comparative scheme of the human PrimPol synthesis reactions, outlining the essential difference between
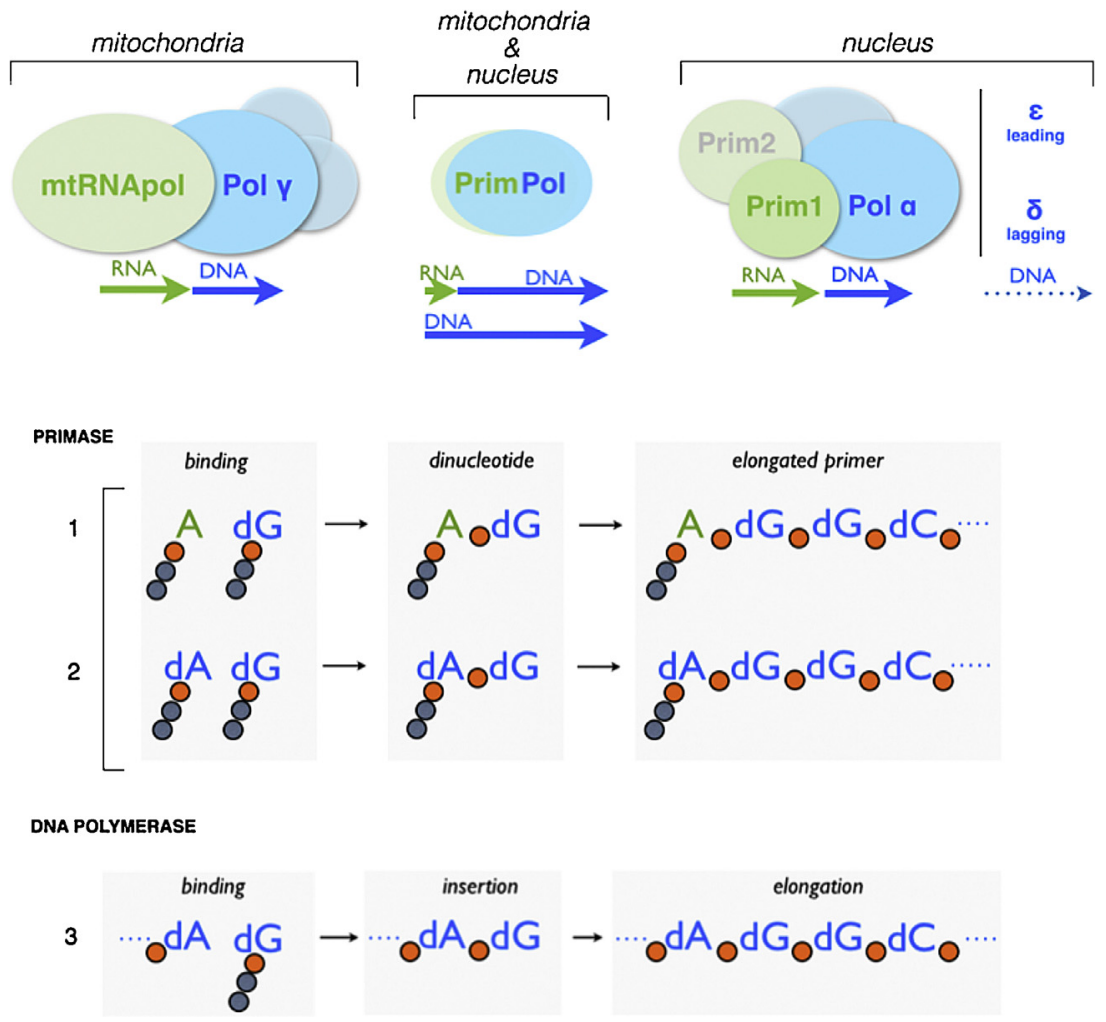

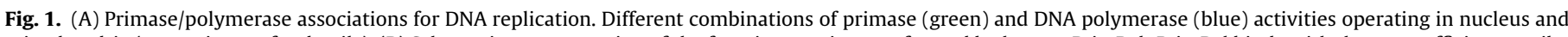

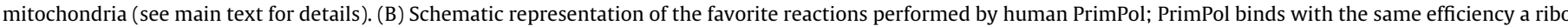

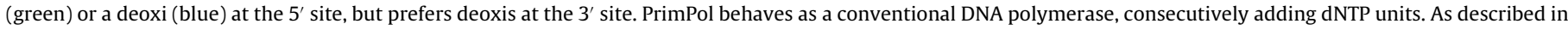
this paper, PrimPol behaves also as RNA polymerase (not shown in the scheme). 
being a primase or a polymerase: only a primase has room for accepting a triphosphate group at the $5^{\prime}$-site, whereas a polymerase needs a primer-terminus with just a single phosphate, engaged in a phosphodiester bond.

\subsection{Functional consequences of PrimPol depletion}

As already mentioned, PrimPol is present in both nuclear and mitochondrial DNA compartments [20]. PrimPol activity could be detected in mitochondrial lysates from human and mouse cells, but was absent in mitochondria derived from a viable PRIMPOL knock-out (KO) mouse model [20]. Strikingly, PRIMPOL gene silencing or ablation in human and mouse cells impaired mitochondrial DNA replication. This first in vivo data, together with PrimPol's enzymatic potential, translesion synthesis capabilities, and synergy observed with replicative DNA polymerases Pol $\gamma$ and Pole, allowed us to propose that PrimPol would facilitate replication fork progression by acting as a translesion synthesis (TLS) DNA polymerase, or as a specific DNA primase reinitiating downstream of lesions that block synthesis during both mitochondrial and nuclear DNA replication [20]. No other TLS polymerase has been described to operate in mitochondria.

Conversely, during nuclear DNA replication several error-prone translesion synthesis (TLS) DNA polymerases such as Poln, Polı, Polк, Pol $\zeta$ and Rev1 [23,24] could facilitate fork progression through damaged DNA, at the cost of being less selective in their incorporation of dNTPs into the nascent strand. Alternatively, certain lesions could be avoided to speed up replicative fork progression, leaving unreplicated DNA gaps to be repaired at a later time. Such a lesion-skipping mechanism would imply the initiation of a new DNA strand, a step that strictly requires a primase activity. By using both PrimPol-depleted Hela cells and PRIMPOLKO MEFs, we demonstrated that PrimPol promotes uninterrupted fork progression after UV-irradiation and facilitates the restart of stalled forks after a temporary depletion of dNTPs [25]. Moreover, by using a "separation of function mutant" devoid of a specific Znfinger, we and others were able to show that the role of PrimPol in rescuing replicative stressed forks depends on its primase activity, and is needed to maintain genomic stability during nuclear DNA replication $[22,25]$.

In this article we revise the different solutions provided by PrimPol to tolerate DNA lesions, especially those involving template and primer dislocations that can be operating during both mitochondrial and nuclear DNA replication. Moreover, the capacity to extend RNA chains, and insert ribonucleotides opposite DNA lesions as 8oxoG, suggest that PrimPol could also operate as a translesion synthesis partner during DNA-directed RNA synthesis, particularly during mitochondrial DNA transcription.

\section{Results and discussion}

\subsection{PrimPol, specialist in tolerating 8oxoG template lesions}

One of the most common forms of oxidative damage, 8-oxo-deoxyguanine (80xoG), occurs at a frequency of $10^{3}-10^{4}$ events/cell/day [26,27]. Unrepaired 8oxoG lesions are a threat for genome stability, causing $\mathrm{G}: \mathrm{C}$ to $\mathrm{T}$ :A transitions during DNA replication [28]. In human cells, a specialized DNA polymerase from family X, DNA polymerase lambda ( $\operatorname{Pol} \lambda$ ), contributes to the efficiency of BER by reverting 8oxoG:dAMP mismatches to 8oxoG:dC "correct" pairs, by means of a MutYH-initiated error-free tolerance reaction, in which Pol $\lambda$ inserts $\mathrm{dC}$ opposite 8 oxoG, and performs its efficient extension [29,30]. That mismatch repair-like reaction has two benefits: (1) correcting the errors made opposite 8oxoG; (2) giving a second chance to the BER pathway to eliminate
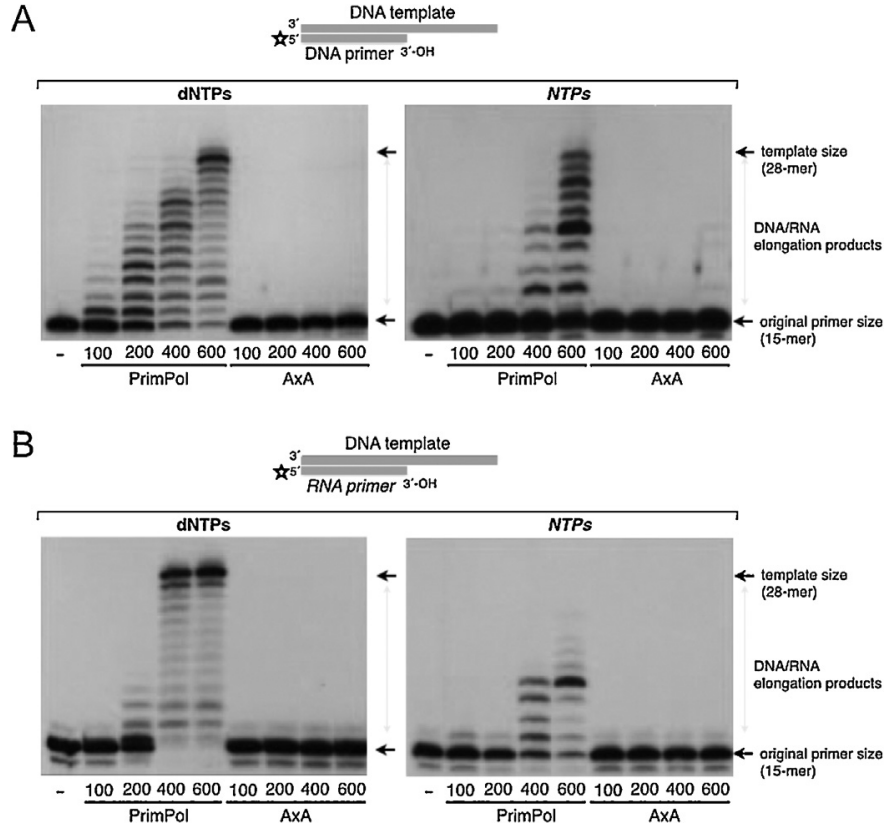

Fig. 2. PrimPol is a DNA polymerase and also a RNA polymerase. Elongation of a 15-mer DNA primer (A) or RNA primer (B) annealed to a DNA template, with $10 \mu \mathrm{M}$ dNTP or NTP, and in the presence of increasing concentration of either human PrimPol or a null mutant AxA $(100,200,400,600 \mathrm{nM})$. The two type of substrates (dNTPs and NTPs) were incorporated by PrimPol into both DNA and RNA primers.

the damaged 8oxoG base. Most recently, we showed that another polymerase, PrimPol, has an unprecedented capacity to tolerate 8oxoG lesions [20], in large contrast with replicases as human Poly $[31,54]$. A detailed kinetic study of the capability of human PrimPol to read the 8oxoG lesion has been recently carried out [32], confirming our previous findings about the high efficiency of PrimPol to tolerate this lesion [20], and showing a significant preference to insert dCMP versus dAMP opposite the 80xoG templating base.

Our working model is that one of the main functions of PrimPol during mitochondrial DNA replication is to facilitate progression across 8oxoG lesions [20]. Further work will be required to demonstrate that hypothesis in vivo, and the consequences of either the absence of PrimPol, or the impact of PrimPol in combination with Pol $\gamma$ variants associated to mitochondriopathies.

\subsection{PrimPol behaves both as a DNA polymerase and a RNA polymerase. Implications for translesion synthesis}

By using defined substrates for both the primase and polymerase reactions, we demonstrated that the active site of PrimPol has a preference for distributively inserting dNTPs, based on a 10-100-fold-higher affinity for deoxys versus ribonucleotides at the $3^{\prime}$ incoming nucleotide binding site. On the other hand, there is no such a large preference regarding the $5^{\prime}$ binding site (the primer site). That implies that PrimPol can bind equally well either a ribonucleotide or a deoxynucleotide at the $5^{\prime}$-site during the formation of an initiating dinucleotide (the primase reaction), but prefers a deoxynucleotide at the 3 -site of the dimer, and subsequently during its further extension steps [20].

Interestingly, as shown in Fig. 2B, PrimPol can use a polyribonucleotide (RNA) strand as a convenient primer, to be extended with both incoming dNTPs and rNTPs; however, the incorporation of rNTPs is much less efficient than incorporation of dNTPs, regardless the nature (DNA versus RNA) of the primer (see Fig. 2A and B). By using as a control an inactive version of PrimPol, mutated at two catalytic metal ligands (AxA; [20]), these 4 different reactions were shown to be intrinsic to PrimPol and not due to contaminant DNA or 
RNA polymerases from scherichia coli (the expression source). Qualitative analysis demonstrated that the nucleotide insertion fidelity of PrimPol, either as DNA polymerase or as an RNA polymerase, is similar, preferentially inserting the complementary nucleotide dictated by the DNA template (Fig. S1).

Supplementary material related to this article can be found, in the online version, at http://dx.doi.org/10.1016/j.dnarep. 2015.02.013.

The capacity of extending RNA primers with dNTPs mimics the specificity of eukaryotic Pol $\alpha$, a specialized DNA polymerase in charge of converting an RNA primer (made by the conventional Pri1 primase) into a DNA primer, largely preferred by the Pol $\varepsilon$ and

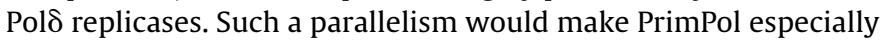
useful for extending the initiating RNA transcript used during initiation of mtDNA replication at both oriH and oriL, that would be immediately transferred to the mitochondrial replicase Pol $\gamma$.

Another speculation, based on the capacity to extend RNA strands with rNTPs would be that PrimPol could help to tolerate DNA lesions during transcription itself. Fig. 3A shows that PrimPol efficiently extends a pre-existing DNA primer by inserting a ribonucleotide opposite an 8oxoG DNA lesion. Such an insertion is quite accurate, preferentially inserting CTP (from 0.1 to $10 \mu \mathrm{M}$ ), and much less efficiently ATP. Similarly, as shown in Fig. 3B, an equivalent RNA primer can be also extended with CTP $(10 \mu \mathrm{M})$, and less with ATP $(10 \mu \mathrm{M})$, as valid readouts when copying the 8oxoG lesions.

In conclusion, it is tempting to speculate that the lesion bypass capacity of PrimPol can facilitate the extension of both DNA (during DNA replication) and RNA (during transcription) primers across DNA lesions as 8oxoG. That hypothesis could be especially relevant during mitochondrial transcription, as it operates across intensively damaged DNA, and the mitochondrial RNA polymerase frequently stalls at oxidative lesions in the template [33]. In such a case, the mechanism of PrimPol recruitment to stalled transcription machinery, shown to imply a direct interaction with the single-stranded binding protein RPA [22], should be significantly different than during mitochondrial or nuclear DNA replication. As a dedicated helicase is not required during transcription, DNA damage-induced "transcriptional stress" with the concomitant accumulation of single-stranded template DNA is not expected to occur.

\subsection{PrimPol can tolerate distortions of both template and primer strands}

Replicases processively extend perfectly paired primers, and make a full copy of the template by reading, one by one, all consecutive templating bases. However, other DNA polymerases more specialized to deal with damaged templates, as Pol $\mu$, Pol $\lambda$, etc., are distributive and can handle terminal mismatches, or various distortions at the two DNA strands. Such a potential is the basis for their role in NHEJ, where they use very limited microhomologies to bridge the two ends of a DSB, thus tolerating discontinuities or distortions during base pairing [34,35]. It has been also described that several polymerases can bypass non-informative lesions, as abasic sites, just by directly copying the next available templating base.

PrimPol is a DNA-directed DNA and RNA polymerase that distributively inserts both deoxy and ribonucleotides. Here we show examples of non-orthodox reactions catalyzed by PrimPol when copying a non-damaged template strand, and discuss the implications for damage tolerance. Fig. 4A shows that PrimPol extends the primer strand by preferentially copying the first available templating base (upper panel), but it is also able to skip it, copying the next base (lower panel). That dislocation error, that could potentially produce a frameshift of -1 nucleotide, implies the
A 3'CTAGTGTCACTCATGXTCTATGTGAAGA 5' 5 ' GATCACAGTGAGTAC
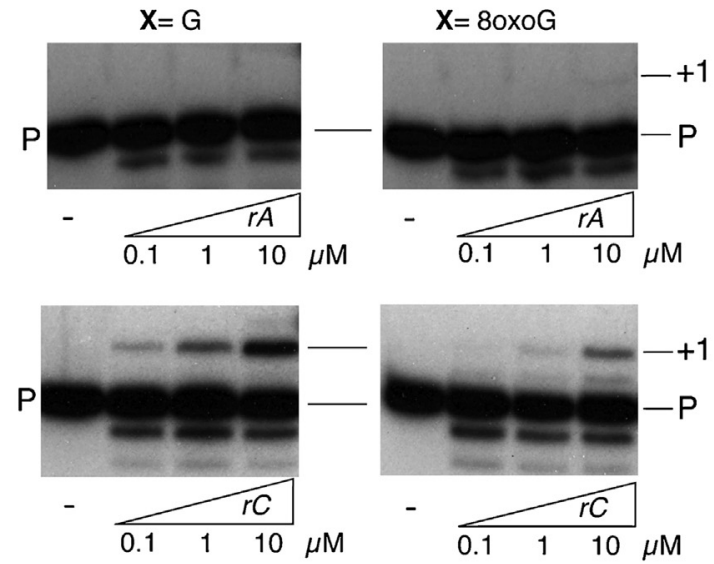

B

3'CTAGTGTCACTCATGXTCTATGTGAAGA 5' 5 'GAUCACAGUGAGUAC
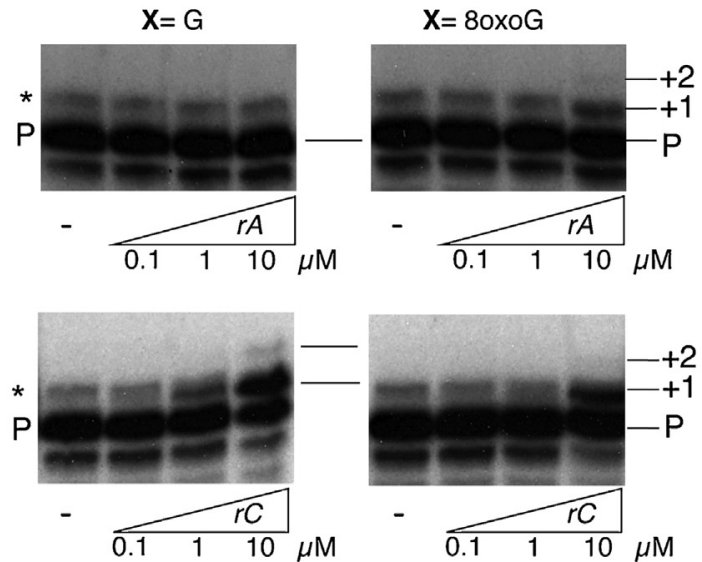

Fig. 3. Bypass of the 8 oxoG lesion by PrimPol using ribonucleotides. The activity was measured on two different template/primer structures, either having a DNA primer (A) or an RNA primer (B). X indicates the +1 template nucleotide that can be either dG (as a control) or its oxidized form 8oxoG. PrimPol ( $200 \mathrm{nM})$ could extend both DNA and RNA primers by preferentially inserting CTP opposite 8oxoG. The band indicated with an asterisk (running slightly slower than the bona-fide +1 product) is an artifact as it appears in the absence of added nucleotides.

need to tolerate a dislocated template base without implying relocation of the terminal base pair. That template dislocation event is favored by providing higher concentrations of $\mathrm{dA}$ (lower panel), and consequently is described as "dNTP selection-mediated". PrimPol likely uses this mechanism to bypass abasic sites [20]. Alternatively, that pattern of $\mathrm{dA}$ misinsertion and extension could be explained if PrimPol misinserts $A$ opposite $C$ and extends the mispair by inserting another $A$ opposite the $T$.

A slightly different dislocation event can be produced when the templating base to be copied is identical to the one forming the 3 '-terminal base pair (the primer-terminus). Fig. 4B shows the example of a repetition of two Gs. Again, PrimPol preferentially extends the primer with $\mathrm{dC}$, but there is also a significant insertion of $\mathrm{dA}$ even at $10 \mu \mathrm{M}$ (upper panel), that can be further improved by providing higher concentrations of this nucleotide (middle panel). In this case, the dislocation event is favored by slippage of the template strand, producing a single base distortion $(\mathrm{dG})$ preceding the new but identical terminal base pair. Fig. 4B also shows that an increase in the concentration of $\mathrm{dC}$, the correct nucleotide, can 
A

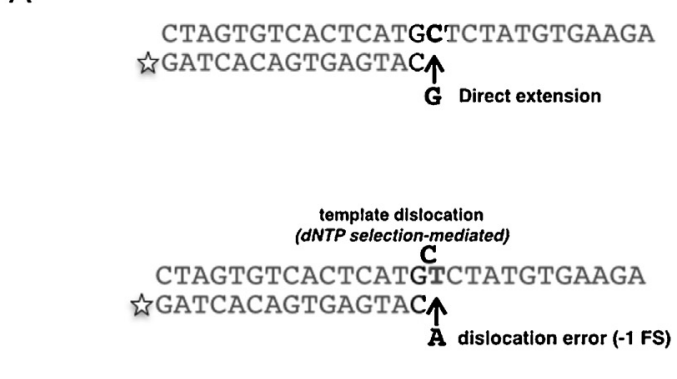

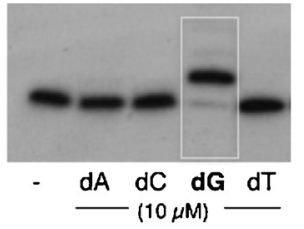

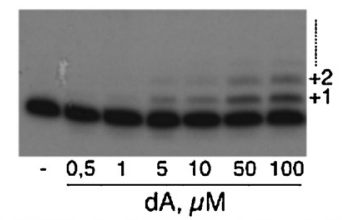

B
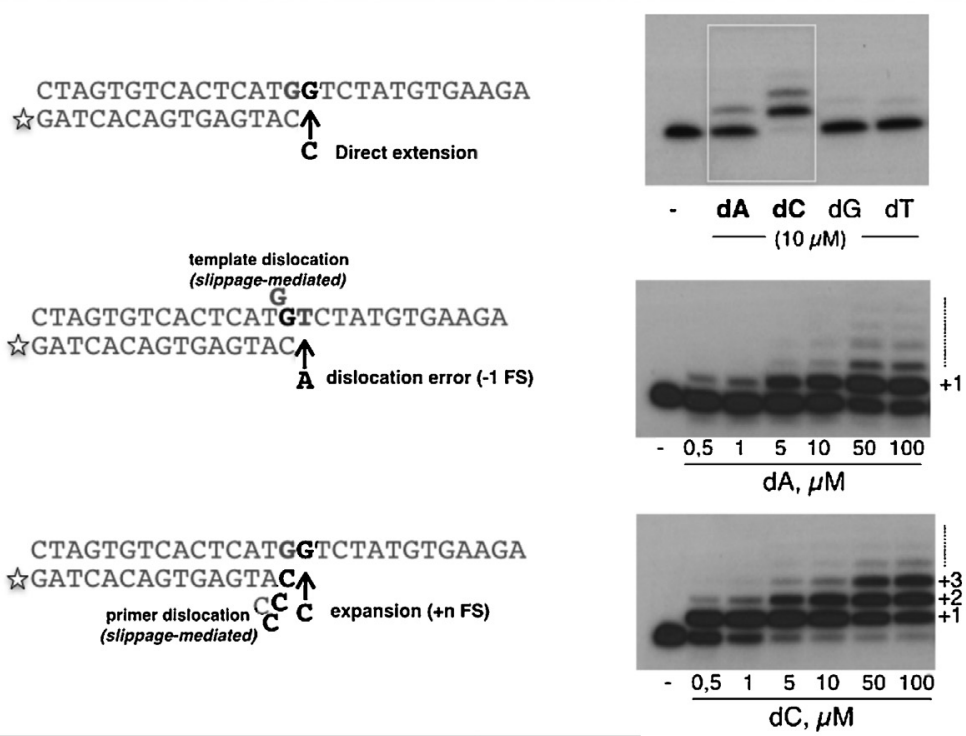

C
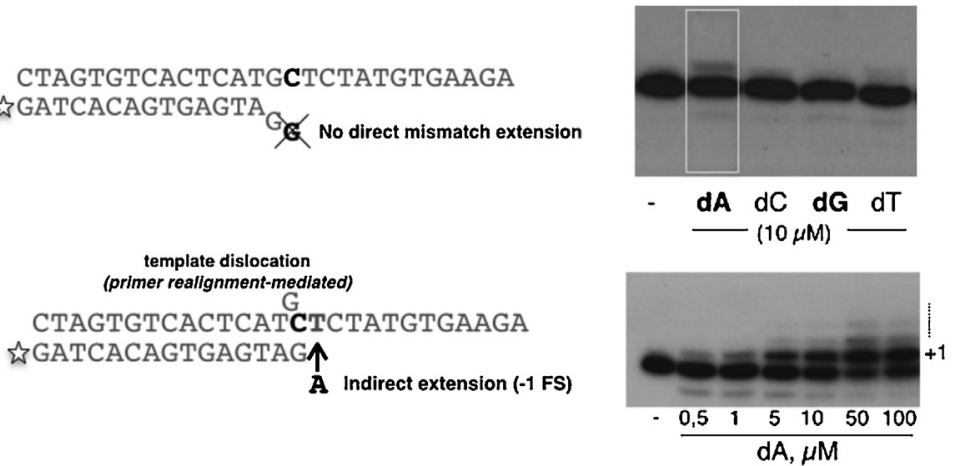

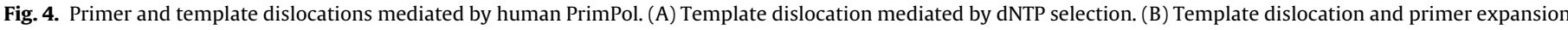
mediated by slippage. (C) PrimPol-mediated primer realignment in order to obtain a matched $3^{\prime}$ primer terminus. See main text for details.

produce an expansion that is mediated by reiterative slippage of the primer strand. That could imply that PrimPol only establishes very exiguous contacts with the primer during polymerization. A similar behavior has been recently described in the case of human Pol $\mu[36]$.

Finally, the experiment shown in Fig. 4C evaluates the same template context as that in Fig. 4A, but in this case with a mismatched $(\mathrm{dG}: \mathrm{dG})$ primer-terminus. PrimPol was very inefficient in inserting the next nucleotide $(\mathrm{dG})$, a direct mismatch extension reaction, indicating a preference for a perfectly paired primer-terminus (upper panel); conversely, some incorporation of dA is already observed at a low $(10 \mu \mathrm{M})$ nucleotide concentration. The efficiency of this reaction, that can be improved by providing higher concentrations of $\mathrm{dA}$ (lower panel), is based on the realignment of the $3^{\prime}$-terminal base of the primer to form a correct base pair with the closest complementary base. For this primer realignment to occur, a single base distortion in the template (dG), preceding the newly formed base pair, has to be tolerated. That dislocation event mimics the one described in Fig. 4B (middle panel), and also implies a potential -1 frameshift. Interestingly, these tolerance to admit distortions of both template and primer strands in the vicinity of the active site, could provide PrimPol with a versatile framework to avoid DNA damage by skipping different DNA lesions.

\subsection{PrimPol generates indels in short homopolymeric sequences}

We have examined the fidelity of DNA synthesis by human PrimPol in the M13mp2 forward assay used before to measure the fidelity of other polymerases from different families (Table 1). PrimPol is relatively error prone, with a base substitution rate $\left(51 \times 10^{-5}\right)$ in the range of substitution rates of family $\mathrm{X}$ polymerases and the single nucleotide indel rate $\left(310 \times 10^{-5}\right)$ similar to 
Table 1

PrimPol fidelity relative to other polymerases.

\begin{tabular}{|c|c|c|c|}
\hline \multirow{3}{*}{$\begin{array}{l}\text { Polymerase } \\
\text { hPrimPol }\end{array}$} & \multirow{3}{*}{$\begin{array}{l}\text { Family } \\
\text { AEP }\end{array}$} & \multicolumn{2}{|c|}{ Error rate $\times 10^{-5}$} \\
\hline & & Base sub. & 1 nuc. indels \\
\hline & & $51(39)$ & $310(232)$ \\
\hline hPoln & $\mathrm{Y}$ & 3500 & 370 \\
\hline hPolk & $\mathrm{Y}$ & 580 & 260 \\
\hline hPol $\lambda$ & $\mathrm{X}$ & 90 & 470 \\
\hline hPol $\beta$ & $\mathrm{X}$ & 23 & 14.5 \\
\hline yPol $\delta$ & B & $<1.3$ & 1.4 \\
\hline yPole & B & $<2.0$ & 1.1 \\
\hline hPol $\gamma$ & A & $<1.0$ & $<0.1$ \\
\hline
\end{tabular}

Data for PrimPol are from this study and from a manuscript in preparation; the error rates are calculated based on mutations generated in four independent PrimPol gap filling reactions. The products of the four reactions yielded similar mutant frequencies, with the average mutant frequency of $19.6 \pm 2.2 \%$. In parenthesis is the number of mutations observed.

Error rates for pols $\eta, \kappa, \varepsilon$ and $\beta$ are from Scherbakova et al. [57] and references therein; for Pol $\lambda$ from Bebenek et al. [55]; for Pol $\delta$ from Fortune et al. [58]; for Pol $\gamma$ from Longley et al. [59].

the rates of $\mathrm{Y}$ family polymerases. Thus, PrimPol generates indels at a 6 -fold higher rate than base substitutions, an unusual behavior shared only by the X family member, Pol $\lambda$. However, unlike Pol $\lambda$, which produces mainly single nucleotide deletions, PrimPol generates minus- and plus- 1 indels, predominantly in short homopolymeric sequences, at a similar rate (Fig. 5A-C). This specificity suggests that PrimPol can equally well accommodate DNA
A

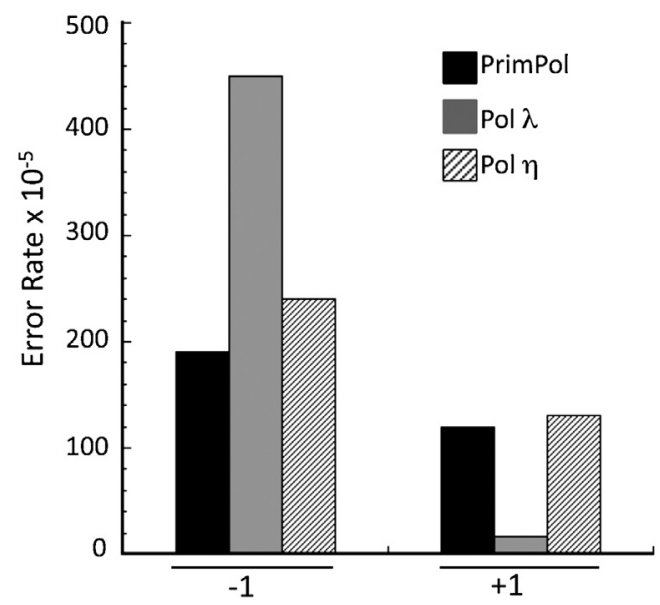

$B$

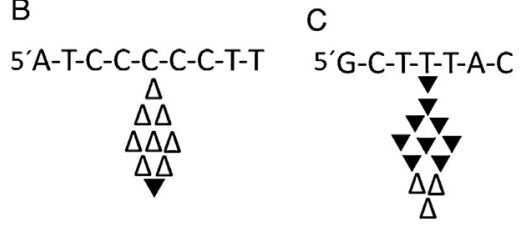

D S'A-G-C-G-A-A-G-A-C -

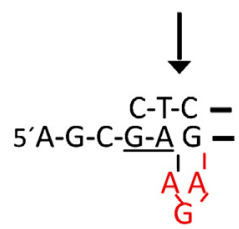

Fig. 5. Mutational specificity of human PrimPol. (A) PrimPol -1 and +1 nucleotide error rates, relative to the rates of pols $\lambda$ and $\eta$. Rates for pols $\lambda$ and $\eta$ are from [55,56], respectively; (B) a single-nucleotide deletion hot spot (at a $C$ run, position 132-136 in the lac $Z \alpha$ complementation sequence, where position 1 is the first transcribed nucleotide) from the PrimPol mutational spectrum. (C) An example of a PrimPol single-nucleotide addition hot spot at a $T$ run, position -36 to -34 of the lacZ $\alpha$ sequence. A deletion and an addition of a nucleotide are represented by an open and filled triangle, respectively; (D) a model for a three-nucleotide deletion from the PrimPol mutation spectrum, between direct, two-base repeats. The deleted nucleotides are red and the dinucleotide repeats are underlined. substrates that have an unpaired base either in the template or the primer strand. The observed propensity of PrimPol to generate indels is consistent with recently published results [37]. Another characteristic feature of the PrimPol mutational spectrum are complex errors (involving nucleotide substitutions, deletions and additions) and short deletions. The sequence specificity of the short deletions suggests that at least some may be generated by primer relocation between direct nucleotide repeats as short as two (Fig. 5D), or even one nucleotide. This behavior may be relevant to PrimPols ability to bypass DNA lesions.

\subsection{PrimPol can induce distant primer-realignments to skip unreadable and bulky DNA lesions, and promote connectivity of separate DNA strands}

We have recently shown that human PrimPol can bypass unreadable template lesions as abasic sites [20], or those caused by UV irradiation, as the 6-4 pyrimidine pyrimidones (6-4 PP; [25]), looping out (not copying) the damaged nucleotides. In these reports, the two lesions were embedded in a sequence context highly favorable to distant primer realignments mediated by human PrimPol. Fig. 6A and B (see also Fig. S2) illustrates the bypass by human PrimPol of a 6-4 PP lesion flanked by the identical sequence "CTAC", a substrate kindly provided by Professor Iwai (Osaka University). In contrast to the complete elongation observed with the corresponding undamaged template $(+14)$, PrimPol made an incomplete shorter copy of the damaged template $(+8)$, that was strictly dependent on a first incorporation of dCTP (complementary to the template guanine located 5 positions downstream to the lesion) followed by incorporation of dTTP and dGTP (data not shown; [25]). These observations fit with a model in which the primer is realigned by PrimPol to a downstream position, based on the existing repetition (CTAC), effectively looping out the lesion without copying it (Fig. 6B, central scheme; Fig. S2B, Scheme 4). The very same mechanism of primer realignment by PrimPol has also been reported when bypassing abasic sites in an identical sequence context [20]. More detailed analysis indicates that these kind of distant primer realignment events, that we named "pseudo-TLS" [25], can be driven by microhomologies as short as 2 and even 1 nucleotides (Fig. S3).

Supplementary material related to this article can be found, in the online version, at http://dx.doi.org/10.1016/j.dnarep. 2015.02.013.

Is that feature shared by other PrimPols? PrimPol enzymes are primitive ancestors of the DNA replication machinery in which two, or even the three basic biochemical activities required at a replication fork (helicase, primase and polymerase) were combined in a single polypeptide. The first PrimPol described, encoded by plasmid pRN1 of Sulfolobus islandicus, has an N-terminal domain containing the primase and polymerase, and a C-terminal region contains a DNA helicase [17]. To date, no data has been reported suggesting a similar TLS capacity by pRN1 PrimPol. Another PrimPol, BcMCM, encoded by a prophage integrated in the Bacillus cereus genome [38] has been recently characterized. In addition of having an active MCM-like helicase, BcMCM mirrors the enzymatic activities of human PrimPol, being both a DNA polymerase, and a primase able to start DNA synthesis starting from dNTPs [16]. As shown in Fig. S2A, BcMCM shares with human PrimPol also the capacity to realign primers to skip unreadable lesions as a 6-4PP: the limited elongation products observed are identical with the two enzymes, and can be explained by a similar capacity to realign the primer strand beyond the lesion (Fig. S2B).

We next tested if this extraordinary potential of PrimPol (only paralleled by Pol $\mu[35,39,40]$ and $\operatorname{Pol} \theta[41,42]$ could allow the "connection" of two non-complementary oligonucleotides by virtue of existing microhomologies. That was indeed the case, as various 

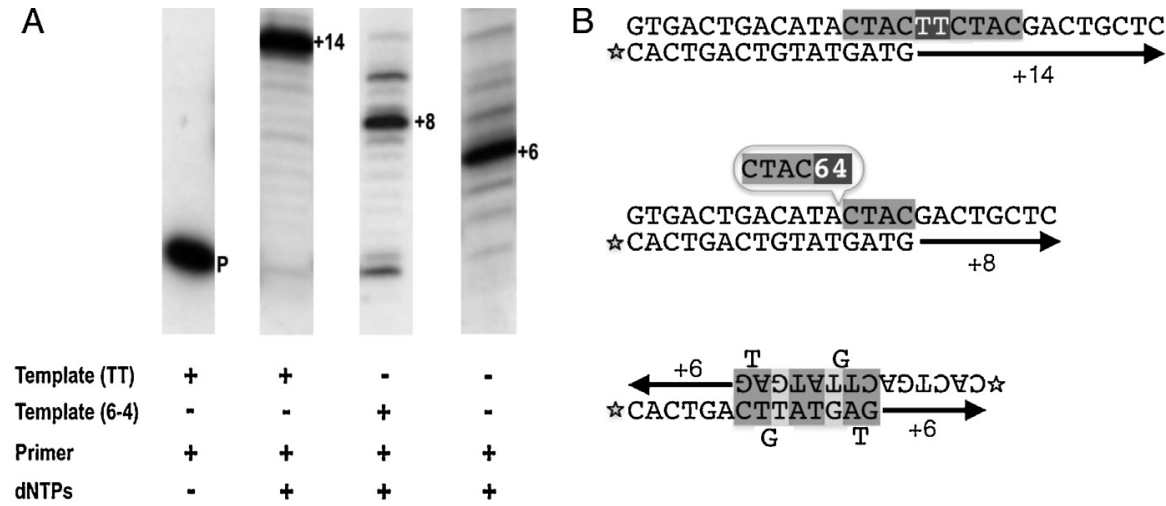

C

Template / Primer

$\mathrm{D}$

Primer
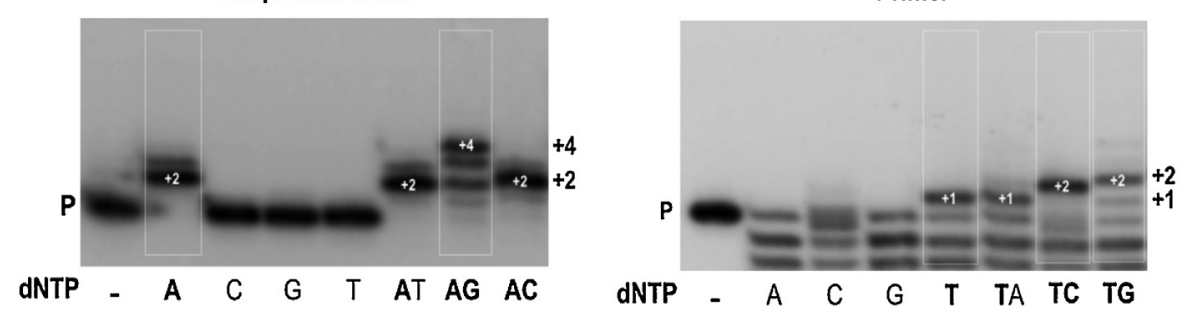

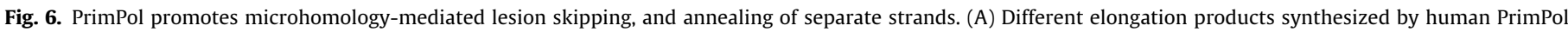

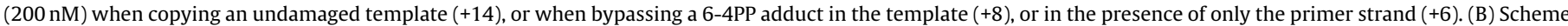

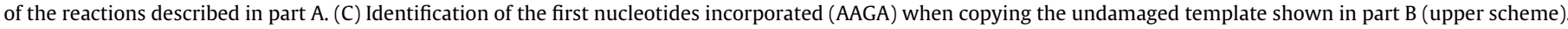

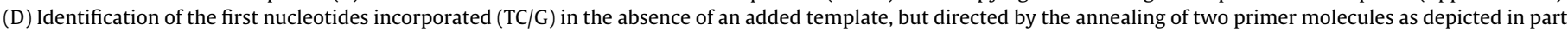
B (bottom scheme).

single-stranded heteropolymeric oligonucleotides could be readily elongated by PrimPol upon addition of the four dNTPs, again in a reaction activated by the presence of $\mathrm{Mn}^{2+}$ ions (see an example in Fig. 7A). Analysis of the first nucleotides incorporated was compatible with the prediction of the most favorable connectivity of two ssDNA molecules (see scheme in Fig. 7A). Another example comes from an important control in the experiment described in Fig. $6 \mathrm{~A}$ (the bypass of a 6-4PP lesion in a template strand). Strikingly, when using only the primer strand, extension was very efficient but produced a different main elongated product $(+6)$, that can be explained by the connection of two primer molecules, based on microhomologies (see Fig. 6B, lower scheme); in this example, two single base pairs (interrupted by one base distortion) are enough to provide a correctly paired primer-terminus for extension by PrimPol, copying the remaining part of the second molecule, thus leading to $a+6$ extended product. Analysis of the identity of the first nucleotides inserted in these conditions demonstrated that $\mathrm{T}$ was the first, followed by a dC or a dG (Fig. 6D), in good agreement with the connection proposed. It has been claimed that human PrimPol can directly read a 6-4PP lesion [21]. In that report, where both the primer and damaged template molecules had identical sequences to those used in our study, it was concluded that PrimPol directly reads the $6-4 \mathrm{PP}$ lesion by inserting a $\mathrm{T}$, followed by either a $\mathrm{dC}$ or a $\mathrm{dG}$, and further extended until a +6 product. Considering that this outcome is identical to the one shown here when providing just the primer oligonucleotide, the conclusion that PrimPol can read a 6-4PP lesion must be taken with some caution.

Finally, by using a homopolymeric ssDNA (poly-dT), we evaluated if PrimPol has an intrinsic terminal transferase activity that could facilitate connectivity of two non-complementary strands. As shown in Fig. 7B, PrimPol did not extend poly-dT neither with dC, dG nor dT, but only dATP (complementary to the poly-dT oligonucleotide) was repeatedly incorporated. That indicates that
PrimPol has no terminal transferase activity, but is capable of connecting two ssDNA strands even when they are strictly noncomplementary.

In conclusion, the unusual capacity of PrimPol to induce distant primer-realignments can be used to skip unreadable and bulky DNA lesions, but also to promote connectivity of separate DNA strands, opening the possibility of a role of PrimPol in alternative forms of NHEJ.

\subsection{Manganese is the preferred PrimPol metal activator}

We have previously shown that PrimPol has a strong preference for $\mathrm{Mn}^{2+}$ over $\mathrm{Mg}^{2+}$ as activator of its DNA synthesis reaction, either as a primase or as a polymerase [20]. Importantly, whereas PrimPol can use a relatively low concentration of $\mathrm{Mn}^{2+}$ ions $(10-50 \mu \mathrm{M})$ to efficiently catalyze its primase activity and polymerase activities, physiological concentrations of $\mathrm{Mg}^{2+}$ ions (5-10 mM) are inhibitory of its DNA polymerization activity; moreover, a concentration of $10 \mu \mathrm{M} \mathrm{Mn}^{2+}$, in or even below the physiological range, was more efficient than a physiological concentration of $10 \mathrm{mM} \mathrm{Mg}^{2+}$ [20]. This preference of human PrimPol for $\mathrm{Mn}^{2+}$ ions has been confirmed by a recent study indicating that $\mathrm{Mn}^{2+}$ enhances its DNA binding ability by 34 -fold, and its polymerase activity up to 1000 -fold, based on steady-state kinetic parameters [32].

Fig. 8A shows that a relatively low concentration of $\mathrm{MnCl}_{2}$ $(50 \mu \mathrm{M})$ allows human PrimPol to efficiently bypass the 8oxoG lesion. Moreover, a primer-realignment/pseudo-TLS event (used here to skip an abasic site in the template), characterized by the appearance of $\mathrm{a}+11$ elongated product, can occur only at a moderate $(200 \mu \mathrm{M}) \mathrm{MnCl}_{2}$ concentration (Fig. 8B, right panel). A moderate $\mathrm{Mn}^{2+}$ ions concentration is also required to promote connectivity of two separate strands (data not shown). It has been discussed for a long time the physiological role of the $\mathrm{Mn}^{2+}$ ions particularly 
A

\section{$5 * \overline{\text { CGCGCACTCACGTCCCCGCC }}$}

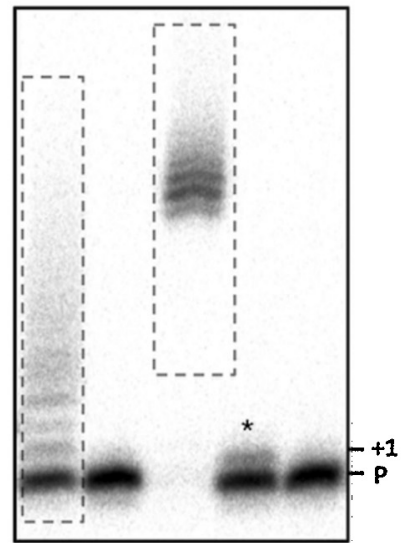

dNTPS dT dG dC dA

B

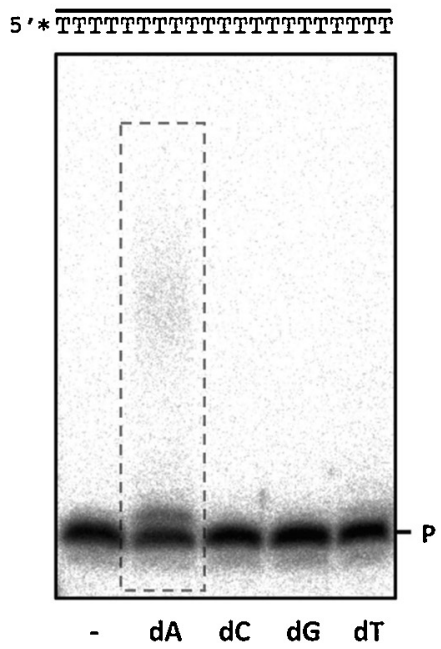

5. $\overline{\text { CGCGCACTCACGTCCCCGCC }}$

Partially

complementary

end-bridging
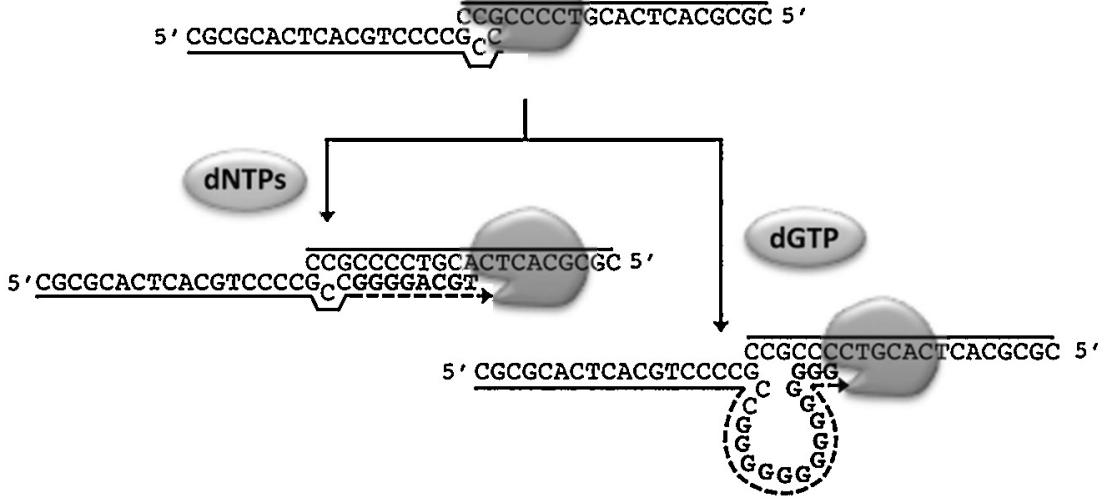

$5 \cdot \overline{\text { TTTTTTTTTTTTTTTTTTTT }}$

Noncomplementary end-bridging

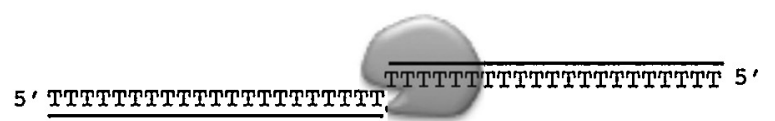

dATP

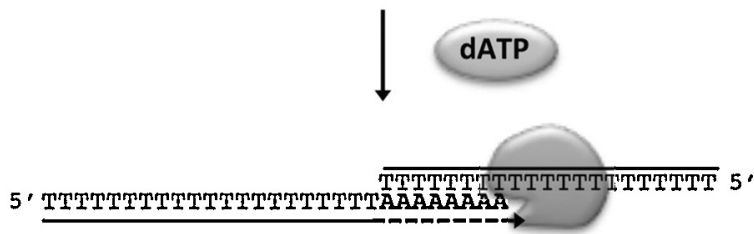

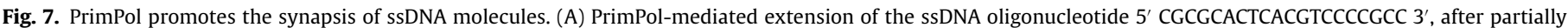

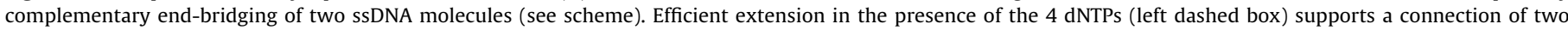

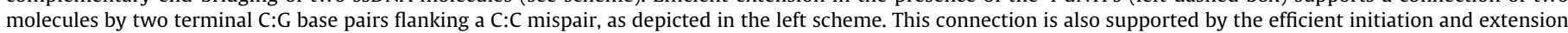

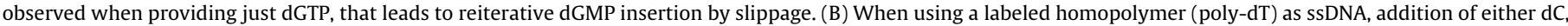

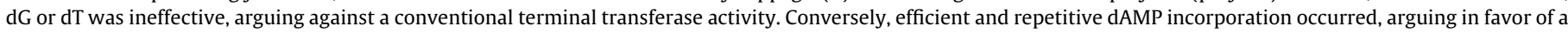
PrimPol-mediated non-complementary synapsis of two poly-dT molecules (see the scheme).

during oxidative stress [43]. Strikingly, although the intracellular manganese has been measured to be around $10 \mu \mathrm{M}$ [44], these levels can increase up to $1-3 \mathrm{mM}$ in some bacteria, as a response to genotoxic damage [45]. Moreover, mitochondria under oxidative stress uptake high concentrations of $\mathrm{Mn}^{2+}$ ions [46]. Thus, an important issue requiring further studies is how these two cations, $\mathrm{Mn}^{2+}$ and $\mathrm{Mg}^{2+}$, compete for PrimPol active site, both in the nucleus and inside the mitochondria.

Is $\mathrm{Mn}^{2+}$ the preferred metal activator for other DNA polymerases? Some specialized polymerases, such as Polı, clearly prefer to utilize manganese even when magnesium is present in a large molar excess [47]. It has been described that human Pol $\lambda$ is adapted to use physiological concentrations of $\mathrm{Mn}^{2+}$ ions $[48,49]$. In the case of human Pol $\mu$ [50], the peak of polymerase activity with NHEJ substrates is reached at the physiological concentration of $\mathrm{Mn}^{2+}$ ions, with no adverse effects on fidelity, while $\mathrm{Mg}^{2+}$ is inhibitory under the same conditions [35]. $\mathrm{M}$. tuberculosis LigD, an AEP-related enzyme involved in bacterial NHEJ, prefers manganese as metal activator, either during gap filling and damage tolerance reactions $[18,19]$, and specially when performing NHEJ reactions [51,52]. Finally, both primase and polymerase activities of a bacterial PrimPol orthologue, BcMCM, also showed a preference for $\mathrm{Mn}^{2+}$ as activating metal ions [16].

In conclusion, although DNA replicases use $\mathrm{Mg}^{2+}$ to improve nucleotide insertion fidelity, other polymerases are tailored to maximize efficiency (at a fidelity cost) of catalytically difficult reactions, by using $\mathrm{Mn}^{2+}$ ions that can boost DNA binding, nucleotide binding and catalysis at their active sites. Human PrimPol, like some other primases and DNA polymerases involved in translesion synthesis, DNA repair, and variability, has a preference for activating $\mathrm{Mn}^{2+}$ ions instead of the more conventional $\mathrm{Mg}^{2+}$ ions. 
A

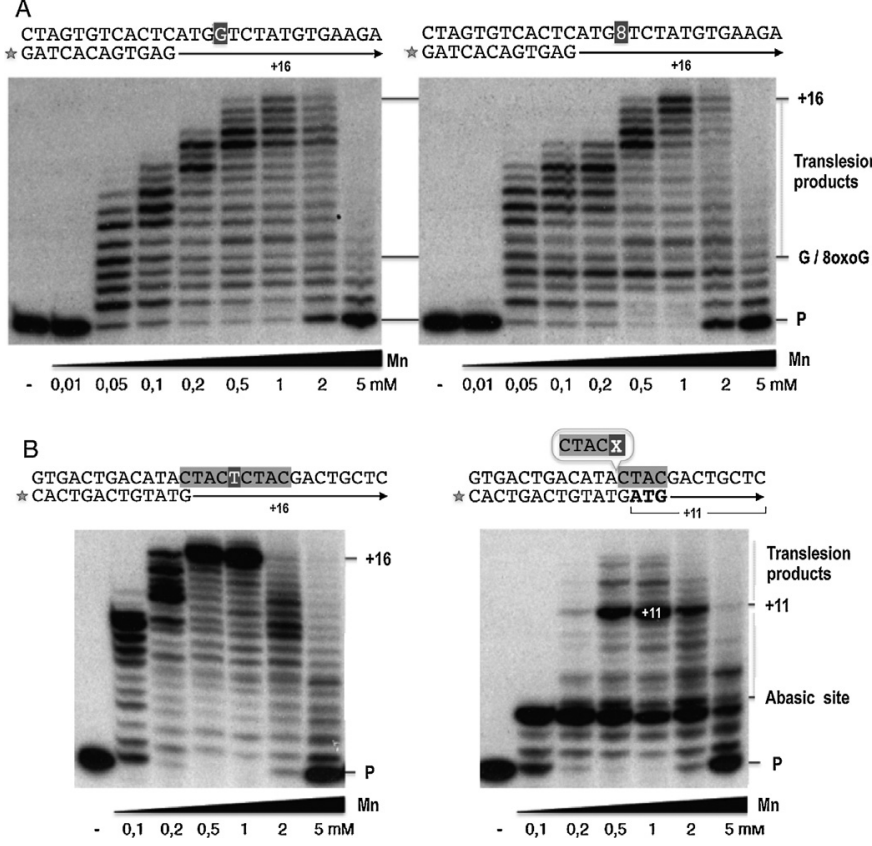

Fig. 8. Manganese concentration required for PrimPol-mediated translesion synthesis. Comparative analysis of PrimPol polymerization across an 80xoG-containing template (A), or an abasic site (B), flanked by a direct repetition (boxed in gray), as a function of $\mathrm{MnCl}_{2}$ concentration. Control templates are shown at the left panels. Polymerization by PrimPol $(200 \mathrm{nM})$ was evaluated at $10 \mu \mathrm{M}$ dNTPs. The schemes show the expected full elongation products $(+16)$, or a shorter main product $(+11)$ obtained by primer realignment ahead of the lesion ( $\mathrm{X}=$ abasic site), after an initial extension of 3 nts (ATG).

\subsection{From translesion synthesis to priming, and evolutionary view}

PrimPol is present in different organisms, from bacterias to archeas and eukaryotes, and in the latter it operates at both DNA compartments, nucleus and mitochondria. PrimPol, an "all terrain" DNA polymerase with the capacity to restart DNA synthesis when needed, i.e. to bypass damaged templates, probably evolved as one of the most antique solutions to facilitate replication of small genomes threatened by environmental damage.

Presumably, DNA damage tolerance mechanisms had to operate very early in evolution, much before the appearance of DNA repair mechanisms to erase DNA damage. In those circumstances, the appearance of DNA lesions in the template strand would represent road blocks hampering progression of a replicative DNA polymerase. That stalling would produce the accumulation of unreplicated ssDNA regions due to unperturbed and continuous helicase action, that could be temporarily covered and protected by an ancestral SSB (Fig. 9A). In that scenario, a versatile enzyme with translesion synthesis capabilities, as PrimPol, was probably crucial to restart DNA synthesis. Fortunately, PrimPol can take advantage of multiple key solutions for translesion synthesis (Fig. 9B). If the lesion is "readable", as an $80 x o G$, it behaves as a conventional TLS polymerase, inserting a nucleotide opposite the lesion; if the lesion is "unreadable", as a 6-4 photoproduct or an abasic site, PrimPol can induce primer realignments to skip the lesion (pseudo-TLS); finally, as an ultimate solution, PrimPol can use single nucleotides (either deoxy or ribo) as "soluble nanoprimers" to initiate synthesis beyond the unreadable lesion (TLS primase).

These hierarchical solutions are probably related to PrimPol's preference to bind open template regions, as those arising during replicative stress, as its main DNA binding determinant, and to its interaction with both RPA [22] and mitochondrial SSB (our unpublished data; [37]). Additionally, PrimPol does not require extensive contacts with a primer strand, thus facilitating the search for

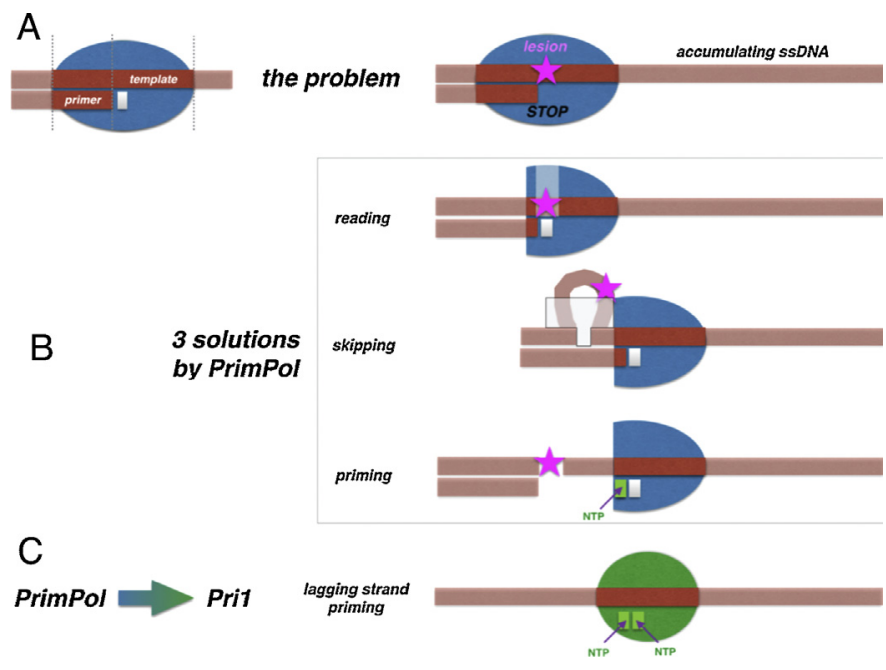

Fig. 9. Alternative solutions for translesion DNA synthesis by human PrimPol. (A) DNA replication is stalled when the replicative DNA polymerase encounters a lesion in the template DNA, accumulating ssDNA ahead of the lesion. (B) Prim$\mathrm{Pol}$ is able to resolve this problem by 3 different mechanisms, depending on the nature of the lesion: (1) directly reading lesions as 8oxoG, acting as a conventional TLS polymerase; (2) skipping unreadable lesions (abasic sites, 6-4PP, etc.) by microhomology-mediated primer realignment ahead of the lesion, acting as a "pseudo" TLS polymerase; (3) synthesizing a new primer ahead of the lesion, as a TLS primase. (C) PrimPol can be considered the archetype of more conventional primases operating in the lagging strand, that are specialized in making RNA primers exclusively.

microhomologies beyond an unreadable damage, as a way to skip the lesion. It is tempting to speculate that the primase function of PrimPol, shown to be critical to re-initiate stalled replication forks during nuclear DNA replication $[22,25]$ was invented as a solution for translesion synthesis, just by reducing the requisites for the primer to a minimum: the use of a single nucleotide (very likely an abundant purine ribonucleotide as ATP) as a primer, but being mainly a DNA synthesizing enzyme. If that hypothesis is correct, and PrimPol was the arquetype of a primase, it is conceivable that the modern primases in charge of making RNA primers for Okazaki fragment synthesis at the lagging strand could have evolved from a gene duplication event of an ancestral PrimPol (Fig. 9C). Accordingly, modern primases would have been adapted to exclusively insert ribonucleotides, as RNA primers can be specifically recognized and further removed, thus avoiding fidelity issues associated to the initiation of DNA synthesis by a non-proofreading enzyme.

\subsection{Future perspectives}

As revised in this paper, PrimPol offers multiple solutions for translesion DNA synthesis. Further studies will be required to determine which solutions operate in each DNA compartment, and the consequences for genome stability. The impact of PrimPol in the accumulation of 80xoG in mtDNA, and the mutagenic consequences of that accumulation, is currently under study by ultradeep sequencing of mtDNA derived from a murine PrimPol knock-out (KO) model that has been recently described [20]. Furthermore, and given that NER is not operating in mtDNA, it can be predicted that PrimPol-mediated small deletions would be produced after UV-irradiation, if these lesions are bypassed by pseudo TLS. Presumably, bypassing DNA lesions in mitochondrial DNA by virtue of PrimPol's TLS primase would be an inconvenient, due to the limited enzymology operating in this cellular compartment. Conversely, that solution appears to be tailored for nuclear DNA replication, where other specialized TLS enzymes can operate at the gaps left behind after the repriming event. Regarding the impact of PrimPol in human pathology, it is conceivable that alterations in PrimPol 
function, affecting the balance between primase and polymerase activities, or affecting its translesion synthesis capacity, could affect cell proliferation and alter sensitivity to DNA damaging agents used in human cancer therapy.

\section{Materials and methods}

\subsection{Protein, oligonucleotides and nucleotides}

Human wild-type PrimPol and the null mutant AxA (D114A, E116A) were purified as previously described [20]. BcMCM was obtained as described [16]. DNA and RNA oligonucleotides were synthesized by Sigma Aldrich (UK). Oligonucleotides containing 8oxoG were purchased to Eurogentec (Belgium). Unlabelled ultrapure dNTPs and rNTPs were supplied by GE. $\left[\gamma^{32} \mathrm{P}\right]$ ATP, obtained from Perkin Elmer, was used for oligonucleotide 5'-labeling by T4 polynucleotide kinase (New England Biolabs).

\subsection{DNA/RNA polymerase assays on template/primer molecules}

DNA polymerase assays were done using a template/primer structure. A 5'-32 P-labeled 15-mer oligonucleotide primer (DNA or RNA 5' GATCACAGTGAGTAC 3') was hybridized to a 28-mer oligonucleotide template ( $5^{\prime}$ AGAAGTGTATCTTGTACTCACTGTGATC $\left.3^{\prime}\right)$. The reaction mixture $(20 \mu \mathrm{L})$ contained buffer $\mathrm{R}$ (50 mM Tris- $\mathrm{HCl} \mathrm{pH} 7.5,40 \mathrm{mM} \mathrm{NaCl}, 1 \mathrm{mM}$ DTT, 2.5\% glycerol, $0.1 \mathrm{mg} / \mathrm{mL} \quad \mathrm{BSA}), 1 \mathrm{mM} \quad \mathrm{MnCl}_{2}, 2.5 \mathrm{nM}\left[\gamma_{-}{ }^{32} \mathrm{P}\right]$-labeled template/primer DNA/RNA, dNTP or rNTP at $100 \mu \mathrm{M}$, and purified human PrimPol wild-type or the null mutant AxA (100, 200, 400 and $600 \mathrm{nM}$ ). After $60 \mathrm{~min}$ at $30^{\circ} \mathrm{C}$, reactions were stopped by addition of formamide loading buffer (10 mM EDTA, 95\%, v/v formamide, $0.3 \%, \mathrm{w} / \mathrm{v}$ xylen-cyanol) and loaded in $8 \mathrm{M}$ urea-containing $20 \%$ polyacrylamide sequencing gels. After electrophoresis primer extension was detected by autoradiography.

\section{3. $80 x o G$ TLS assays}

For "standing start" analysis of 8oxoG translesion, a 5'${ }^{32}$ P-labeled 15-mer oligonucleotide primer (DNA or RNA; 5' GATCACAGTGAGTAC $3^{\prime}$ ) was hybridized to a 28-mer oligonucleotide template ( $5^{\prime}$ AGAAGTGTATCT(X)GTACTCACTGTGATC 3'; $X$ stands for $G$ or $80 x o G$ ) and used to evaluate PrimPol translesion synthesis in the presence of different NTPs. The reaction $(20 \mu \mathrm{L})$ in buffer $\mathrm{R}$ and $1 \mathrm{mM} \mathrm{MnCl}_{2}$ contained $200 \mathrm{nM}$ PrimPol and increasing concentrations $(0.1,1.10 \mu \mathrm{M})$ of ATP or CTP. For "running start" 80xoG translesion DNA synthesis experiments, a 5'-32 P-labeled 12-mer oligonucleotide (5' GATCACAGTGAG 3') was hybridized to the previous templates. Reactions were done in buffer $\mathrm{R}$ and various concentrations of $\mathrm{MnCl}_{2}$ were used to define the range of metal activation. $100 \mu \mathrm{M}$ dNTP and PrimPol $200 \mathrm{nM}$ were added to the reaction mixture. Reaction were incubated at $30^{\circ} \mathrm{C}$ during $60 \mathrm{~min}$, then stopped and analyzed as described above.

\subsection{Primer and template dislocation assays}

To evaluate the PrimPol capacity to induce distortions in the template or primer, two different DNA substrates were used, by hybridizing a $5^{\prime}-{ }^{32}$ P-labeled 15 -mer oligonucleotide ( $5^{\prime}$ GATCACAGTGAGTAC $3^{\prime}$ ) to the following templates: 5' AGAAGTGTATCTCGTACTCACTGTGATC 3'; 5' AGAAGTGTATCTGGTACTCACTGTGATC $3^{\prime}$. For mismatched extension assays, a 5'-32 P-labeled 15-mer oligonucleotide (5' GATCACAGTGAGTAG $3^{\prime}$ ) was hybridized to 5' AGAAGTGTATCTCGTACTCACTGTGATC 3'. Assays were performed in buffer $\mathrm{R}, 1 \mathrm{mM} \mathrm{MnCl}_{2}, 2.5 \mathrm{nM}$ of the DNA/primer indicated, $200 \mathrm{nM}$ PrimPol, and the indicated type and concentration of deoxynucleotides. Reactions were incubated at $30^{\circ} \mathrm{C}$ during $20 \mathrm{~min}$, and the primer extension products were analyzed as described above.

\subsection{Forward mutation assay}

The assay scores errors in the M13mp2 LacZ $\alpha$ gene during synthesis to fill a 407-nucleotide gap [53]. Reaction mixtures $(25 \mu \mathrm{L})$ contained $0.2 \mathrm{nM}$ gapped M13mp2 DNA, $50 \mathrm{mM}$ Tris- $\mathrm{HCl} \mathrm{pH} 8$, $1 \mathrm{mM}$ DTT, $5 \%$ glycerol, $0.1 \mathrm{mg} / \mathrm{mL}$ BSA, $5 \mathrm{mM} \mathrm{MgCl}_{2}$, and $1 \mathrm{mM}$ dNTPs. Reactions were initiated by adding PrimPol at one of the four concentrations: $100 \mathrm{nM}, 200 \mathrm{nM}, 400 \mathrm{nM}, 500 \mathrm{nM}$, and incubated at $37^{\circ} \mathrm{C}$ for $60 \mathrm{~min}$ and terminated by adding EDTA to $15 \mathrm{mM}$. Reaction products were analyzed by agarose gel electrophoresis to verify that gap filling is complete. Correct synthesis produces M13mp2 DNA that yields dark blue phage plaques upon introduction into an E. coli $\alpha$-complementation strain and plating on indicator plates. Errors are scored as light blue or colorless mutants phage plaques. DNA from independent mutant clones was sequenced to define the lacZ mutation. Error rates are expressed as the number of observed mutations divided by the total number of copied nucleotides that were sequenced.

\subsection{Primer realignment-mediated TLS assays}

For 6-4PP TLS experiments, a 5'-32 P-labeled 16-mer oligonucleotide primer ( $5^{\prime}$ CACTGACTGTATGATG $3^{\prime}$ ) was hybridized to either control (undamaged) 30-mer oligonucleotide template $\left(5^{\prime}\right.$ CTCGTCAGCATCTTCATCATACAGTCAGTG $3^{\prime}$ ), or to a damaged template containing an 6-4PP thymine dimer site, kindly provided by S. Iwai (Osaka University, Japan). The reaction mixture $(20 \mu \mathrm{L})$ contained buffer $\mathrm{R}, 1 \mathrm{mM} \mathrm{MnCl} 2,2.5 \mathrm{nM}$ template/primer DNA, the indicated dNTPs $(100 \mu \mathrm{M}$ when the 4 dNTPs were present and $10 \mu \mathrm{M}$ when one or two dNTPs were added) and purified human PrimPol $(200 \mathrm{nM})$. After incubation for $60 \mathrm{~min}$ at $30^{\circ} \mathrm{C}$, primer extension products were analyzed as described above.

For "running start" translesion of an AP site, a $5^{\prime}-{ }^{32} \mathrm{P}-$ labeled 13-mer oligonucleotide primer (5' CACTGACTGTATG 3') was hybridized to either control (undamaged) 30-mer oligonucleotide template ( $5^{\prime}$ CTCGTCAGCATCTTCATCATACAGTCAGTG $3^{\prime}$ ), or to a damaged template (30-mer) containing an AP site $\left(5^{\prime}\right.$ CTCGTCAGCATCT(AP)CATCATACAGTCAGTG 3'; the synthetic abasic nucleotide was obtained from Linktech (UK) and used to customize oligonucleotide synthesis. Reactions were done in buffer $\mathrm{R}$ and various concentrations of $\mathrm{MnCl}_{2}$ were used to define the range of metal activation. $100 \mu \mathrm{M} d N T P$ and PrimPol $200 \mathrm{nM}$ were added to the reaction mixture. Reactions were incubated at $30^{\circ} \mathrm{C}$ during $60 \mathrm{~min}$, then stopped and analyzed as described above.

\subsection{PrimPol-mediated synapsis assays}

Oligonucleotide 5' CGCGCACTCACGTCCCCGCC 3' was used to test the ability of PrimPol to "connect" two identical (noncomplementary) ssDNA molecules. The reaction mixture $(20 \mu \mathrm{L})$ contained buffer $\mathrm{R}, 1 \mathrm{mM} \mathrm{MnCl} 2,5 \mathrm{nM}$ of a $5^{\prime}{ }^{32} \mathrm{P}$-labeled ssDNA molecule, $100 \mu \mathrm{M}$ of the indicated $\mathrm{dNTP} / \mathrm{s}$, and purified human PrimPol ( $400 \mathrm{nM})$. After $60 \mathrm{~min}$ of incubation at $30^{\circ} \mathrm{C}$, extension of the ssDNA molecules was analyzed by $8 \mathrm{M}$-urea PAGE and autoradiography. A similar assay was carried out with a poly-dT(21-mer) substrate, as a control of terminal transferase activity. Finally, the oligonucleotide used as primer in the TLS assays described above (5' CACTGACTGTATGATG $3^{\prime}$ ) was also individually tested (with no complementary template added) for a potential "connection", via microhomology, of two primer molecules. In this case, the reaction mixture $(20 \mu \mathrm{L})$ contained buffer $\mathrm{R}, 1 \mathrm{mM} \mathrm{MnCl}_{2}, 2.5 \mathrm{nM}$ template/primer DNA, the indicated dNTPs ( $100 \mu \mathrm{M}$ when the 4 dNTPs 
were present and $10 \mu \mathrm{M}$ when one or two dNTPs were added) and purified human PrimPol $(200 \mathrm{nM})$. After incubation for $60 \mathrm{~min}$ at $30^{\circ} \mathrm{C}$, primer extension products were analyzed as described above.

\section{Conflict of interest statement}

The authors declare no conflict of interest.

\section{Acknowledgements}

We thank Ian J. Holt and Juan Méndez for helpful discussions, and Shigenore Iwai for the (6-4)pp oligonucleotide. This work was supported by Comunidad de Madrid (S2010/BMD-2361), Spanish Ministry of Economy and Competitiveness (BFU2012-37969) to L.B., by the Division of Intramural Research of the US National Institutes of Health (NIH), National Institute of Environmental Health Sciences project Z01 ES065070 to T.A.K., and by an Institutional grant to Centro de Biología Molecular 'Severo Ochoa' from Fundación Ramón Areces. G.S.-M. and P.C were recipients of a JAE-predoctoral fellowship from the Spanish Council for Scientific Research, and from the Spanish Ministry of Economy and Competitiveness, respectively.

\section{References}

[1] A. Kornberg, T.A. Baker, DNA Replication, 2nd ed., W.H. Freeman \& Company, NY, 1991.

[2] L. Blanco, M. Salas, Characterization and purification of a phage phi 29-encoded DNA polymerase required for the initiation of replication, Proc. Natl. Acad. Sci. U. S. A. 81 (1984) 5325-5329.

[3] T.V. Ilyina, E.V. Koonin, Conserved sequence motifs in the initiator proteins for rolling circle DNA replication encoded by diverse replicons from eubacteria, eucaryotes and archaebacteria, Nucleic Acids Res. 20 (1992) 3279-3285.

[4] M. Della, P.L. Palmbos, H.M. Tseng, L.M. Tonkin, J.M. Daley, L.M. Topper, R.S. Pitcher, A.E. Tomkinson, T.E. Wilson, A.J. Doherty, Mycobacterial Ku and ligase proteins constitute a two-component NHEJ repair machine, Science 306 (2004) 683-685.

[5] D.N. Frick, C.C. Richardson, DNA primases, Annu. Rev. Biochem. 70 (2001) 39-80.

[6] L. Aravind, D.D. Leipe, E.V. Koonin, Toprim, a conserved catalytic domain in type IA and II topoisomerases, DnaG-type primases, OLD family nucleases and RecR proteins, Nucleic Acids Res. 26 (1998) 4205-4213.

[7] L.M. Iyer, E.V. Koonin, D.D. Leipe, L. Aravind, Origin and evolution of the archaeoeukaryotic primase superfamily and related palm-domain proteins: structural insights and new members, Nucleic Acids Res. 33 (2005) 3875-3896.

[8] T.W. Wong, D.A. Clayton, In vitro replication of human mitochondrial DNA: accurate initiation at the origin of light-strand synthesis, Cell 42 (1985) 951-958.

[9] T.W. Wong, D.A. Clayton, Isolation and characterization of a DNA primase from human mitochondria, J. Biol. Chem. 260 (1985) 11530-11535.

[10] T.W. Wong, D.A. Clayton, DNA primase of human mitochondria is associated with structural RNA that is essential for enzymatic activity, Cell 45 (1986) $817-825$.

[11] T.A. Brown, C. Cecconi, A.N. Tkachuk, C. Bustamante, D.A. Clayton, Replication of mitochondrial DNA occurs by strand displacement with alternative lightstrand origins, not via a strand-coupled mechanism, Genes Dev. 19 (2005) 2466-2476.

[12] I.J. Holt, H.E. Lorimer, H.T. Jacobs, Coupled leading- and lagging-strand synthesis of mammalian mitochondrial DNA, Cell 100 (2000) 515-524.

[13] J.M. Fuste, S. Wanrooij, E. Jemt, C.E. Granycome, T.J. Cluett, Y. Shi, N. Atanassova, I.J. Holt, C.M. Gustafsson, M. Falkenberg, Mitochondrial RNA polymerase is needed for activation of the origin of light-strand DNA replication, Mol. Cell 37 (2010) 67-78.

[14] G. Lipps, S. Rother, C. Hart, G. Krauss, A novel type of replicative enzyme harbouring ATPase, primase and DNA polymerase activity, EMBO J. 22 (2003) $2516-2525$

[15] A.A. Bocquier, L. Liu, I.K. Cann, K. Komori, D. Kohda, Y. Ishino, Archaeal primase: bridging the gap between RNA and DNA polymerases, Curr. Biol. 11 (2001) 452-456.

[16] J. Sanchez-Berrondo, P. Mesa, A. Ibarra, M.I. Martinez-Jimenez, L. Blanco, J. Mendez, J. Boskovic, G. Montoya, Molecular architecture of a multifunctional MCM complex, Nucleic Acids Res. 40 (2012) 1366-1380.

[17] G. Lipps, A.O. Weinzierl, G. von Scheven, C. Buchen, P. Cramer, Structure of a bifunctional DNA primase-polymerase, Nat. Struct. Mol. Biol. 11 (2004) $157-162$.
[18] N.C. Brissett, R.S. Pitcher, R. Juarez, A.J. Picher, A.J. Green, T.R. Dafforn, G.C. Fox, L. Blanco, A.J. Doherty, Structure of a NHEJ polymerase-mediated DNA synaptic complex, Science 318 (2007) 456-459.

[19] R.S. Pitcher, N.C. Brissett, A.J. Picher, P. Andrade, R. Juarez, D. Thompson, G.C. Fox, L. Blanco, A.J. Doherty, Structure and function of a mycobacterial NHEJ DNA repair polymerase, J. Mol. Biol. 366 (2007) 391-405.

[20] S. Garcia-Gomez, A. Reyes, M.I. Martinez-Jimenez, E.S. Chocron, S. Mouron, G. Terrados, C. Powell, E. Salido, J. Mendez, I.J. Holt, L. Blanco, PrimPol, an archaic primase/polymerase operating in human cells, Mol. Cell 52 (2013) 541-553.

[21] J. Bianchi, S.G. Rudd, S.K. Jozwiakowski, L.J. Bailey, V. Soura, E. Taylor, I. Stevanovic, A.J. Green, T.H. Stracker, H.D. Lindsay, A.J. Doherty, PrimPol bypasses UV photoproducts during eukaryotic chromosomal DNA replication, Mol. Cell 52 (2013) 566-573.

[22] L. Wan, J. Lou, Y. Xia, B. Su, T. Liu, J. Cui, Y. Sun, H. Lou, J. Huang, hPrimpol1/CCDC111 is a human DNA primase-polymerase required for the maintenance of genome integrity, EMBO Rep. 14 (2013) 1104-1112.

[23] K.E. Zahn, S.S. Wallace, S. Doublié, DNA polymerases provide a canon of strategies for translesion synthesis past oxidatively generated lesions, Curr. Opin. Struct. Biol. 21 (2011) 358-369.

[24] J.E. Sale, A.R. Lehmann, R. Woodgate, Y-family DNA polymerases and their role in tolerance of cellular DNA damage, Nat. Rev. Mol. Cell Biol. 13 (2012) 141-152.

[25] S. Mouron, S. Rodriguez-Acebes, M.I. Martinez-Jimenez, S. Garcia-Gomez, S. Chocron, L. Blanco, J. Mendez, Repriming of DNA synthesis at stalled replication forks by human PrimPol, Nat. Struct. Mol. Biol. 20 (2013) 1383-1389.

[26] K.B. Beckman, B.N. Ames, Oxidative decay of DNA, J. Biol. Chem. 272 (1997) $19633-19636$

[27] H.J. Helbock, K.B. Beckman, M.K. Shigenaga, P.B. Walter, A.A. Woodall, H.C. Yeo, B.N. Ames, DNA oxidation matters: the HPLC-electrochemical detection assay of 8-oxo-deoxyguanosine and 8-oxo-guanine, Proc. Natl. Acad. Sci. U. S. A. 95 (1998) 288-293.

[28] M. Moriya, Single-stranded shuttle phagemid for mutagenesis studies in mammalian cells: 8-oxoguanine in DNA induces targeted G.C. $\rightarrow$ T.A. transversions in simian kidney cells, Proc. Natl. Acad. Sci. U. S. A. 90 (1993) 1122-1126.

[29] A.J. Picher, L. Blanco, Human DNA polymerase lambda is a proficient extender of primer ends paired to 7,8-dihydro-8-oxoguanine, DNA Repair 6 (2007) 1749-1756.

[30] B. van Loon, U. Hübscher, An 8-oxo-guanine repair pathway coordinated by MUTYH glycosylase and DNA polymerase lambda, Proc. Natl. Acad. Sci. U. S. A 106 (2009) 18201-18206.

[31] M.A. Graziewicz, B.J. Day, W.C. Copeland, The mitochondrial DNA polymerase as a target of oxidative damage, Nucleic Acids Res. 30 (2002) 2817-2824.

[32] M.K. Zafar, A. Ketkar, M.F. Lodeiro, C.E. Cameron, R.L. Eoff, Kinetic analysis of human PrimPol DNA polymerase activity reveals a generally error-prone enzyme capable of accurately bypassing 7,8-dihydro-8-oxo-2'deoxyguanosine, Biochemistry 53 (2014) 6584-6594.

[33] S.D. Cline, M.F. Lodeiro, L.J. Marnett, C.E. Cameron, J.J. Arnold, Arrest of human mitochondrial RNA polymerase transcription by the biological aldehyde adduct of DNA, M1dG, Nucleic Acids Res. 38 (2010) 7546-7557.

[34] E. Crespan, T. Czabany, G. Maga, U. Hübscher, Microhomology-mediated DNA strand annealing and elongation by human DNA polymerases lambda and beta on normal and repetitive DNA sequences, Nucleic Acids Res. 40 (2012) 5577-5590.

[35] M.J. Martin, L. Blanco, Evolving DNA repair polymerases: from double-strand break repair to base excision repair and VDJ recombination, in: DNA Repair New Research Directions, InTech, 2013, ISBN 980-953-307-746-3, pp. 85-121.

[36] A. Aza, M.J. Martin, R. Juarez, L. Blanco, G. Terrados, DNA expansions generated by human Polmu on iterative sequences, Nucleic Acids Res. 41 (2013) 253-263.

[37] T.A. Guilliam, S.K. Jozwiakowski, A. Ehlinger, R.P. Barnes, S.G. Rudd, L.J. Bailey, J.M. Skehel, K.A. Eckert, W.J. Chazin, A.J. Doherty, Human PrimPol is a highly error-prone polymerase regulated by single-stranded DNA binding proteins, Nucleic Acids Res. 43 (2015) 1056-1068.

[38] A.T. McGeoch, S.D. Bell, Eukaryotic/archaeal primase and MCM proteins encoded in a bacteriophage genome, Cell 120 (2005) 167-168.

[39] J.F. Ruiz, D. Lucas, E. García-Palomero, A.I. Saez, M.A. González, M.A. Piris, A. Bernad, L. Blanco, Overexpression of human DNA polymerase mu $(\mathrm{Pol} \mu)$ in a Burkitt's lymphoma cell line affects the somatic hypermutation rate, Nucleic Acids Res. 32 (2004) 5861-5873.

[40] M.J. Martin, R. Juarez, L. Blanco, DNA-binding determinants promoting NHEJ by human Polmu, Nucleic Acids Res. 40 (2012) 11389-11403.

[41] M. Hogg, M. Seki, R.D. Wood, S. Doublie, S.S. Wallace, Lesion bypass activity of DNA polymerase theta (POLQ) is an intrinsic property of the pol domain and depends on unique sequence inserts, J. Mol. Biol. 405 (2011) 642-652.

[42] M.J. Yousefzadeh, D.W. Wyatt, K. Takata, Y. Mu, S.C. Hensley, J. Tomida, G.O. Bylund, S. Doublié, E. Johansson, D.A. Ramsden, K.M. McBride, R.D. Wood, Mechanism of suppression of chromosomal instability by DNA polymerase PolQ PLoS Genet. 10 (10) (2014 Oct 2) e1004654, http://dx.doi.org/10.1371/ journal.pgen.1004654.

[43] J.D. Aguirre, V.C. Culotta, Battles with iron: manganese in oxidative stress protection, J. Biol. Chem. 287 (2012) 13541-13548.

[44] D.G. Kehres, M.E. Maguire, Emerging themes in manganese transport, biochemistry and pathogenesis in bacteria, FEMS Microbiol. Rev. 27 (2003) 263-290.

[45] D. Slade, M. Radman, Oxidative stress resistance in Deinococcus radiodurans, Microbiol. Mol. Biol. Rev. 75 (2011) 133-191.

[46] T.E. Gunter, C.E. Gavin, K.K. Gunter, The case for manganese interaction with mitochondria, Neurotoxicology 30 (2009) 727-729. 
[47] E.G. Frank, R. Woodgate, Increased catalytic activity and altered fidelity of human DNA polymerase iota in the presence of manganese, J. Biol. Chem. 282 (2007) 24689-24696.

[48] G. Blanca, I. Shevelev, K. Ramadan, G. Villani, S. Spadari, U. Hübscher, G. Maga, Human DNA polymerase lambda diverged in evolution from DNA polymerase beta toward specific $\mathrm{Mn}(++)$ dependence: a kinetic and thermodinamic study, Biochemistry 42 (2003) 7467-7476.

[49] M. Garcia-Diaz, K. Bebenek, J.M. Krahn, L.C. Pedersen, T.A. Kunkel, Role of the catalytic metal during polymerization by DNA polymerase lambda, DNA Repair (Amst.) 6 (2007) 333-340.

[50] O. Domínguez, J.F. Ruiz, M. García-Díaz, M. Laín, M. González, C. Martínez-A, A. Bernad, L. Blanco, DNA polymerase mu (Pol $\mu$ ), homologous to TdT, could act as a DNA mutator in eukaryotic cells, EMBO J. 19 (2000) 1731-1742.

[51] N.C. Brissett, M.J. Martin, R.S. Pitcher, J. Bianchi, R. Juarez, A.J Green, G.C. Fox, L. Blanco, A.J. Doherty, Structure of a novel pre-ternary complex involving a prokaryotic NHEJ polymerase, Mol. Cell 41 (2011) 221-231.

[52] N.C. Brissett, M.J. Martin, E.J. Bartlett, J. Bianchi, L. Blanco, A.J. Doherty, Molecular basis for DNA double-strand break annealing and primer extension by an NHEJ DNA polymerase, Cell Rep. 5 (2013) 1108-1120.

[53] K. Bebenek, T.A. Kunkel, Analyzing fidelity of DNA polymerases, Methods Enzymol. 262 (1995) 217-232.
[54] M.A. Graziewicz, R.J. Bienstock, W.C. Copeland, The DNA polymerase gamma Y955C disease variant associated with PEO and parkinsonism mediates the incorporation and translesion synthesis opposite 7,8-dihydro-8-oxo-2' deoxyguanosine, Hum. Mol. Genet. 16 (2007) 2729-2739.

[55] K. Bebenek, M. García-Diaz, L. Blanco, T.A. Kunkel, The frameshift infidelity of human DNA polymerase lambda. Implications for function, J. Biol. Chem. 278 (2003) 34685-34690.

[56] T. Matsuda, K. Bebenek, C. Masutani, I.B. Rogozin, F. Hanaoka, T.A. Kunkel, Erro rate and specificity of human and murine DNA polymerase eta, J. Mol. Biol. 312 (2001) 335-346.

[57] P.V. Scherbakova, Y.I. Pavlov, O. Chilkova, I.B. Rogozin, E. Johansson, T.A. Kunkel, Unique error signature of the four-subunit yeast DNA polymerase epsilon, J. Biol. Chem. 278 (2003) 43770-43780.

[58] J.M. Fortune, Y.I. Pavlov, C.M. Welch, E. Hohansson, P.M. Burgers, T.A. Hunkel, Saccharomyces cerevisiae DNA polymerase delta: high fidelity for base substitutions but lower fidelity for single- and multi-base deletions, J. Biol. Chem. 280 (2005) 29980-29987.

[59] M.J. Longley, D. Nguyen, T.A. Kunkel, W.C. Copeland, The fidelity of human DNA polymerase gamma with and without exonucleolytic proofreading and the p55 accessory subunit, J. Biol. Chem. 276 (2001) 38555-38562. 